\title{
Establishment of An Estrogen Receptor-Positive Cell Line (HMA-1) Derived from Human Breast Carcinoma
}

\author{
Shigeo Matano, Noriaki Ohuchi, Hisashi Hirakawa, \\ Tetsuro Nishihira, Motoi Abe, Shozo Mori and Minoru \\ Aкімото* \\ The Second Department of Surgery, Tohoku University \\ School of Medicine, Sendai 980, and *Department of \\ Surgery, Tsukidate Public Hospital, Tsukidate 987-22
}

\begin{abstract}
Matano, S., Ohuchi, N., Hirakawa, H., Nishinira, T., Abe, M., Mori, S. and Aкімото, M. Establishment of An Estrogen Receptor-Positive Cell Line (HMA-1) Derived from Human Breast Carcinoma. Tohoku J. Exp. Med., 1991, 164 (2), 169182 - We have established a novel human breast carcinoma cell line, HMA-1, derived from ascites of a female breast cancer patient. HMA-1 was shown to be an epithelial cell line with intracytoplasmic duct-like vacuoles, microvilli, desmosomes and tonofibrils in accordance with human breast cancer. The cell line demonstrated a good cell growth ability in monolayer fashion with a doubling time of $46 \mathrm{hr}$. Based on a whole cell binding assay the cell line contained estrogen receptor $\left(1.45 \times 10^{-4}\right.$ sites/cell). Tamoxifen, an anti-estrogen agent induced a dose-dependent decrease in the cell growth rate, but estradiol stimulated the cell growth. HMA-1 could be transplanted subcutaneously into BALB/c nude mice, and was able to cause tumors approximately two months after heteroinoculation. These results indicate that HMA-1 cell line may serve as a new human breast carcinoma cell line which could be utilized in the breast cancer research.

breast neoplasm; human cell line; estrogen receptor
\end{abstract}

Breast carcinoma remains the leading cause of cancer mortality among women in western countries and its incidence is rising worldwide including Japan. Human breast carcinoma cell lines are needed for multidisciplinary research in breast cancer. There are a few well-characterized cell lines, derived from human breast carcinomas. The first report attempting to culture breast carcinoma cells appeared in 1937 (Cameron and Chambers), but there were no other reports until 1958 when Lasfargues and Ozzello established the first successful long-term culture of human breast carcinoma cells (BT-20). Since then various kinds of human breast cancer cell lines have been reported (Soule et al. 1973 ; Trempe and Fogh 1973 ; Cailleau et al. 1974 ; Breast Cancer Task Force Cell Culture Bank,

Received April 8, 1991 ; revision accepted for publication May 15, 1991.

Address for reprints : Dr. Noriaki Ohuchi, The Second Department of Surgery, Tohoku University School of Medicine, 1-1 Seiryo-machi, Aoba-ku, Sendai 980, Japan. 
Current Inventory 1977; Engel and Young 1978; Engel et al. 1978). The MCF-7 has contributed to biological analyses of breast cancer cells, i.e., studies on estrogen-receptor, oncogene expression, and tumoricidal effects of chemo-endocrine agents (Butler et al. 1981 ; Sutherland et al. 1983 ; Osborne et al. 1985 ; Gottardis et al. 1989 ; Sommers et al. 1990). Breast cancers differ, however, as far as their biological behavior and tumor cell heterogeneity are concerned (Smith et al. 1984 ; Chu et al. 1985; Band et al. 1990 ; Petersen et al. 1990).

Breast cancer cell lines can be identified as different subgroups on the basis of hormone receptor status, antigenic phenotype or sensitivity to chemotherapeutic agents, which would allow improvement in therapy and have a great impact on biological analysis of breast cancer. Human breast carcinoma cell lines including BT-20, MCF-7 and ZR75-1 have been utilized in the experimental studies of breast cancer. The breast epithelial cell lines, however, differ from one another in the expression of tumor-associated antigens and estrogen receptor. It is therefore important to establish and characterize new reliable human breast cancer cell lines.

In this report we describe a new human breast cancer cell line derived from ascitic cells of a female patient with breast cancer. We have identified the origin of cell line, and examined hormonal effects on cell growth, morphological characterization using phase-contrast and electron microscopes, and tumorigenicity in vivo.

\section{Materials and Methods}

Establishment of cell line

HMA-1 cell line was established from ascites obtained from a 48-year-old premenopause female patient with breast cancer. The clinical staging of the patient according to the TNM classification was $\mathrm{T}_{4} \mathrm{~N}_{2} \mathrm{M}_{1}$ (stage IV) with metastases to the multiple bones and bilateral ovaries. The primary lesion was histologically diagnosed as papillary adenocarcinoma of the breast, and cytological analysis of the ascites revealed the same histological characteristics. After centrifugation at 1,000 rpm for 5 min the ascite cell pellets were passed through $0.83 \% \mathrm{NH}_{4} \mathrm{Cl}$-Tris buffer for exclusion of red blood cells and washed twice in culture medium, RPMI-1640 (Nissui Pharmaceutical Co., Ltd., Tokyo) supplemented with 10\% fetal bovine serum (FBS) (Gibco, Grand Island, NY, USA). The cells were cultured in RPMI-1640 medium in tissue culture flask with an exchange of half volume of the medium every 4 days. The culture was then propagated and passaged through $0.1 \%$ Trypsin with $0.02 \%$ ethylenediaminetetraacetic acid (EDTA) in phosphate-buffered saline (PBS). Fibroblasts were then removed by vigorous pipeting and epithelial cells remained adherent to the surface of Petri dishes.

\section{Cell growth analysis}

Cell growth ability of HMA-1 was analyzed at the 32nd passage of the cell line. Cells of $2.8 \times 10^{5} / 5 \mathrm{ml}$ in medium were cultured in Petri dish for 13 days, counted daily by Coulter Counter and then the doubling time was determined based on the growth curve.

The growth curves were also generated in the medium containing $10^{-7} \mathrm{M}$ to $10^{-8} \mathrm{M}$ of $17 \beta$-estradiol (Sigma, St Louis, MO, USA) as estrogen $\left(\mathrm{E}_{2}\right)$, and $10^{-6} \mathrm{M}$ to $10^{-7} \mathrm{M}$ of Tamoxifen (ICI-Pharma, Ltd., Maccles Field, Cheshire, UK) as an anti-estrogen agent. 17 
$\beta$-Estradiol and Tamoxifen were added on the second day of the culture. The culture medium was exchanged with the medium containing the same concentrations of $17 \beta$ estradiol and Tamoxifen every 4 days. To eliminate an endogeneous steroid activity steroid-depleted FBS was used in the assays: The assay was performed after FBS was treated twice with dextran-coated charcoal $(1 \%$ activated charcoal with $0.1 \%$ dextran; Sigma) using $0.22 \mu \mathrm{m}$ Millipore filter for $30 \mathrm{~min}$ at $55^{\circ} \mathrm{C}$.

\section{Morphological analysis}

Epithelial cell culture was observed under phase-contrast microscope. The cells were fixed in $10 \%$ formalin solution and stained with Hematoxilin-eosin (HE), Giemsa, or Papanicolau stainings, then observed under light microscope.

The cultured cells were propagated in $60 \mathrm{~mm}$ Petri dishes and fixed in $2.5 \%$ glutaraldehyde cacodyl acid buffer ( $\mathrm{pH}$ 7.4) solution for $60 \mathrm{~min}$ at $4{ }^{\circ} \mathrm{C}$ and $2 \%$ osmium tetroxide $\left(\mathrm{OsO}_{4}\right)$ solution for $30 \mathrm{~min}$. The specimens were dehydrated, infiltrated with Epon 812 and sandwiched between teflon-coated cover-slips. Ultrathin sections were cut by a ultramicrotome with a diamond knife. After staining the sections with uranyl acetate and lead acetate we observed and photographed the specimens using a Hitachi H-500 electron microscope (Hitachi).

\section{Chromosome analysis}

The metaphase chromosomes in 100 cells at the 9 th and $73 \mathrm{rd}$ passages were counted. The mid-log phase cells were treated with Colcemid (Boehringer Mannheim Yamanouchi, Tokyo) at a concentration of $0.1 \mu \mathrm{g} / \mathrm{ml}$ for $2 \mathrm{hr}$. The cells were then scraped off from the dish and collected by centrifugation at 1,200 rpm for $5 \mathrm{~min}$. The pellet was then fixed with methanol-acetic acid $(3: 1)$ and stained in $2 \%$ Giemsa solution. The chromosome number and aberrations were counted under microscope. One hunded metaphase spreads were counted for chromosome number and aberrations, then the distribution of chromosomes were investigated through different passages. Marker chromosome (Nelson-Rees et al. 1974) was determined by trypsin-Giemsa banding method using the cells with chromosome number 41 and 42 which were most frequently expressed.

\section{Isozyme analysis}

Isozyme analysis of HMA-1 cell line was carried out using lactate dehydrogenase $(\mathrm{LDH})$, glucose-6-phosphate dehydrogenase (G6PD), aspartate aminotransferase (AST), mannose phosphate isomerase (MPI), purine nucleoside phosphorylase (NP), malate dehydrogenase (MD) and peptidase B (PepB). The mid-log phase cells, $10^{8}$, were rinsed in PBS, detached from the dish using rubber policeman, rinsed again in PBS and centrifuged. The pellet mixed with same amount of buffer $(50 \mathrm{mM}$ Tris-HCI, pH 7.5, $1 \mathrm{mM}$ EDTA, $2 \%$ Triton $\times 100$ ) was sonicated and then centrifuged at $10,000 \mathrm{rpm}$ for $15 \mathrm{~min}$. The supernatant including enzyme-treated cells was collected and the G-banding patterns of isozyme were determined by elecrtrophoresis using Hela S3 cell as a positive control.

\section{Estrogen receptor assay}

Whole-cell binding assay was employed for estrogen receptor analysis. Confluent monolayer cells of HMA-1 in the 34th passage growing in medium were trypsinized, suspended at concentration of $2 \times 10^{5}$ cells $/ \mathrm{ml}$, and cultured 4 days in multiwell dishes. The cultures with serum free-medium containing $\left[{ }^{3} \mathrm{H}\right] \mathrm{E}_{2}\left(0.1\right.$ to $9 \times 10^{-9} \mathrm{M}$ estradiol, 85.9 $\mathrm{Ci} / \mathrm{mmol}$ ) were harvested for receptor determination. The radioactivity was counted in scintilation counter (Aloka 901, Aloka, Tokyo). MCF-7 cells were also investigated for estrogen receptor determination as a positive control. 


\section{Tumorigenicity in vivo}

Four-week-old mice (BALB/c/nu/nu; CLEA Japan, Osaka) were purchased and maintained under specific pathogen-free conditions. To determine whether the HMA-1 cells were tumorigenic, cells $\left(1 \times 10^{8}\right)$ of $73 \mathrm{rd}$ passage were resuspended in FBS-free RPMI-1640 and introduced subcutaneously into the nude mice. The mice were then inspected twice weekly for tumor appearance. Size of the tumors were two-dimensionally measured and approximate volume of the tumors were determined by (length : L) $\times(\text { width : W })^{2} / 2$.

\section{Mycoplasma}

Cultures of HMA-1 stem line in passages 32nd were tested for the presence of Mycoplasma by a Hoechst DNA fluorochrome staining method. All cultures were found to be free of Mycoplasma contamination.

\section{RESULTS}

\section{HMA-1 cell line}

Rapid proliferations of presumptive carcinoma cells and fibroblasts were observed after treatment of ascitic cells in culture medium. On the 78th day after the culture the growth rate of fibroblasts decreased, and the first passage of carcinoma cells was established using trypsin/EDTA. Fibroblasts were completely disappeared after several passages. The cell line has been maintained continuously up to 112nd passage with appropriate growth rate. Bacteria and fungi were not observed in the culture, although we used RPMI-1640 medium without antibiotics. Cultures of HMA-1 stem line were also found to be free of Mycoplasma contamination using a Hoechst DNA fluorochrome staining method.

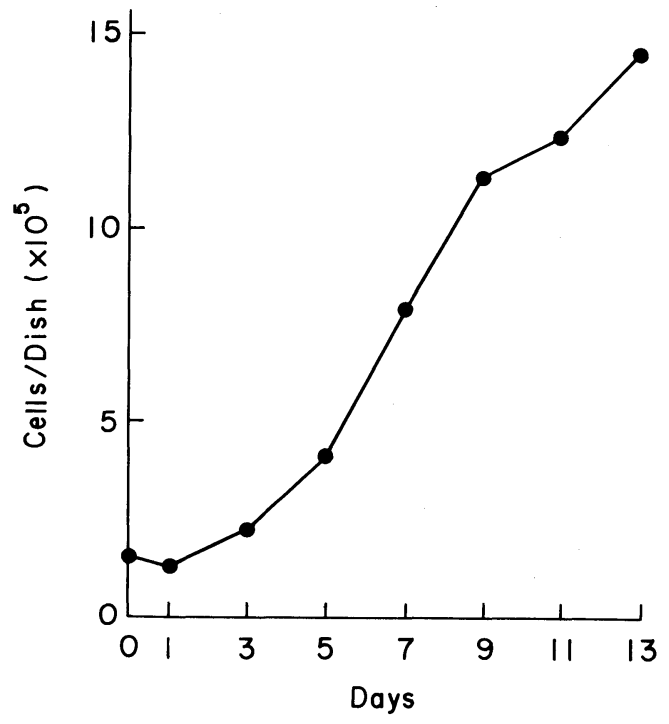

Fig. 1. The growth curve of HMA-1 cell line (passage 32). 


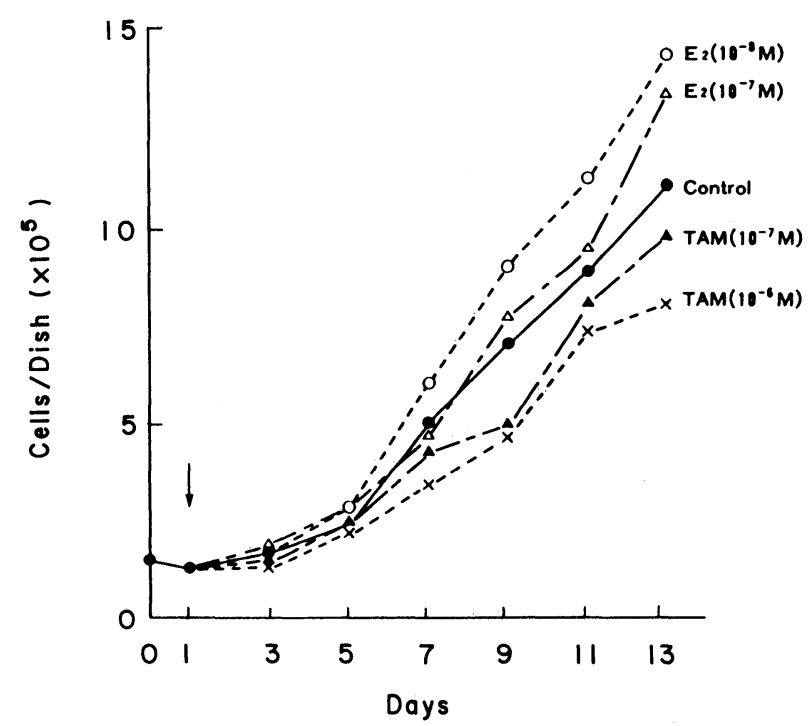

Fig. 2. Hormonal effects on cell proliferation in HMA-1 cells. Tamoxifen (TAM) and $\beta$-estradiol $\left(\mathrm{E}_{2}\right)$ were added on day 1 (arrow).

\section{Cell growth analysis}

Using the 32nd passage of the cell line we examined the cell growth ability. Fig. 1 shows the growth curve of HMA-1 and the doubling time was calculated to be $46 \mathrm{hr}$. We also investigated the effects of hormones on cell proliferation in HMA-1 cell line. On the second day of culture $17 \beta$-estradiol $\left(\mathrm{E}_{2}\right)$ or Tamoxifen was added. The growth was stimulated by $17 \beta$-estradiol on dose-dependent, but was inhibited by Tamoxifen (Fig. 2). As compared to the control cells without hormonal treatment both the increase of cell growth by $17 \beta$-estradiol and the decrease by Tamoxifen were statistically significant $(p<0.05)$. The inhibition of cell growth by Tamoxifen $\left(1 \times 10^{-6} \mathrm{M}\right)$ was completely resuscitated by the addition of estradiol $\left(1 \times 10^{-8} \mathrm{M}\right)$.

\section{Morphological analysis}

Based on phase contrast morphology, primary culture of HMA-1 showed a monolayer, cobble-stone-like appearances resembling adenocarcinoma cells of the breast (Fig. 3). The culture became to be confluent and showed so-called domeform surrounded by epithelial cells in spherical fashion (Fig. 4).

Light microscopic studies revealed that the HMA-1 had characteristics of adenocarcinoma cells with relatively small size of cells with monotonous arrangement, high $\mathrm{N} / \mathrm{C}$ ratio and nuclear mitosis (Fig. 5).

Ultrastructural analysis using electron microscope demonstrated large nuclei with irregular-shape and cytosol abundant with mitochondria (Fig. 6). The 

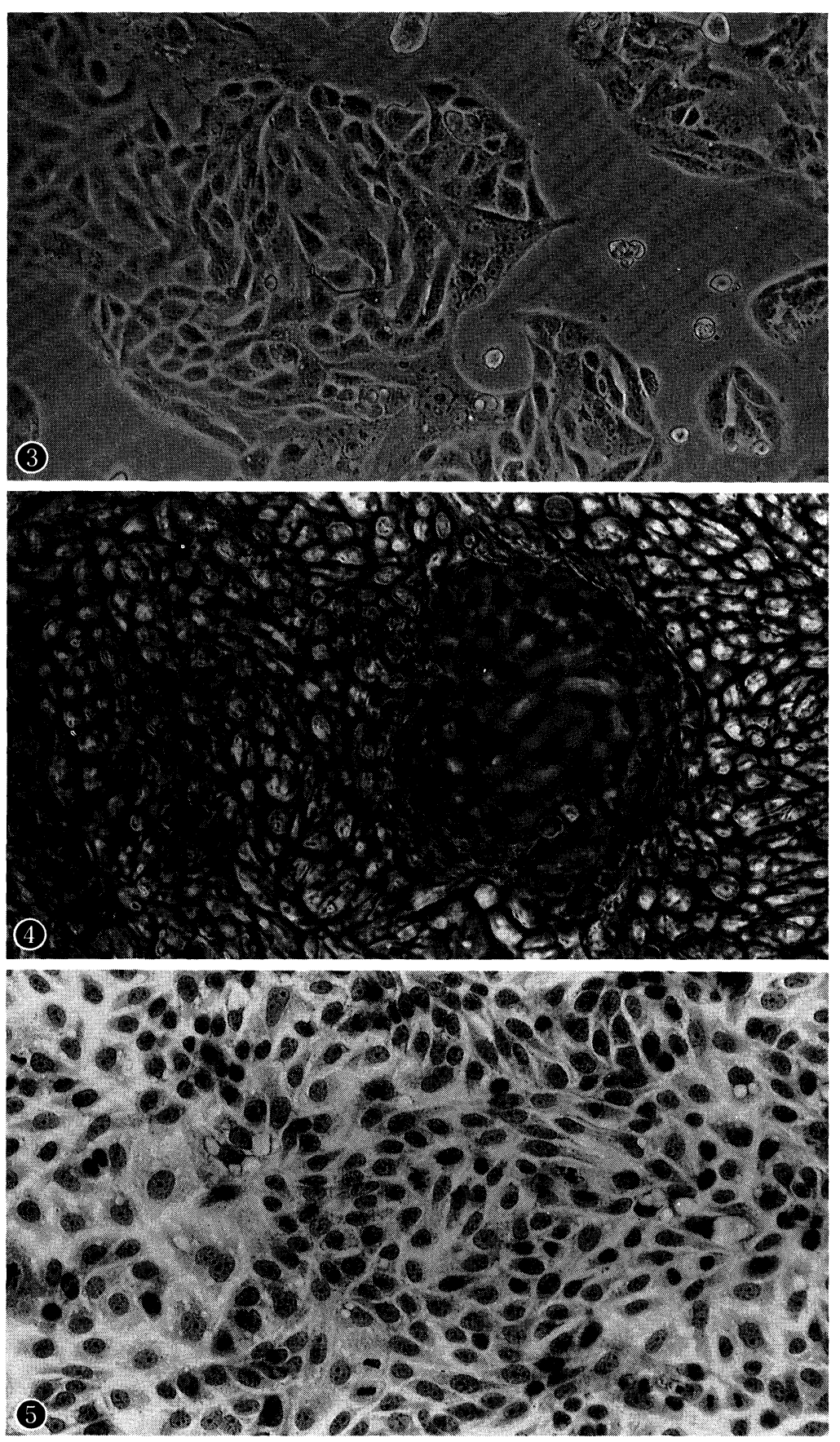

Fig. 3. A phase contrast microscope of HMA-1 cells with epithelial morphology growing in monolayer, cobble-stone-like appearances (passage 13). $\times 200$.

Fig. 4. Confluent HMA-1 cells showing so-called dome-formation (passage 82). $\times 250$.

Fig. 5. Papanicolau staining of HMA-1 cells. $\times 200$. 

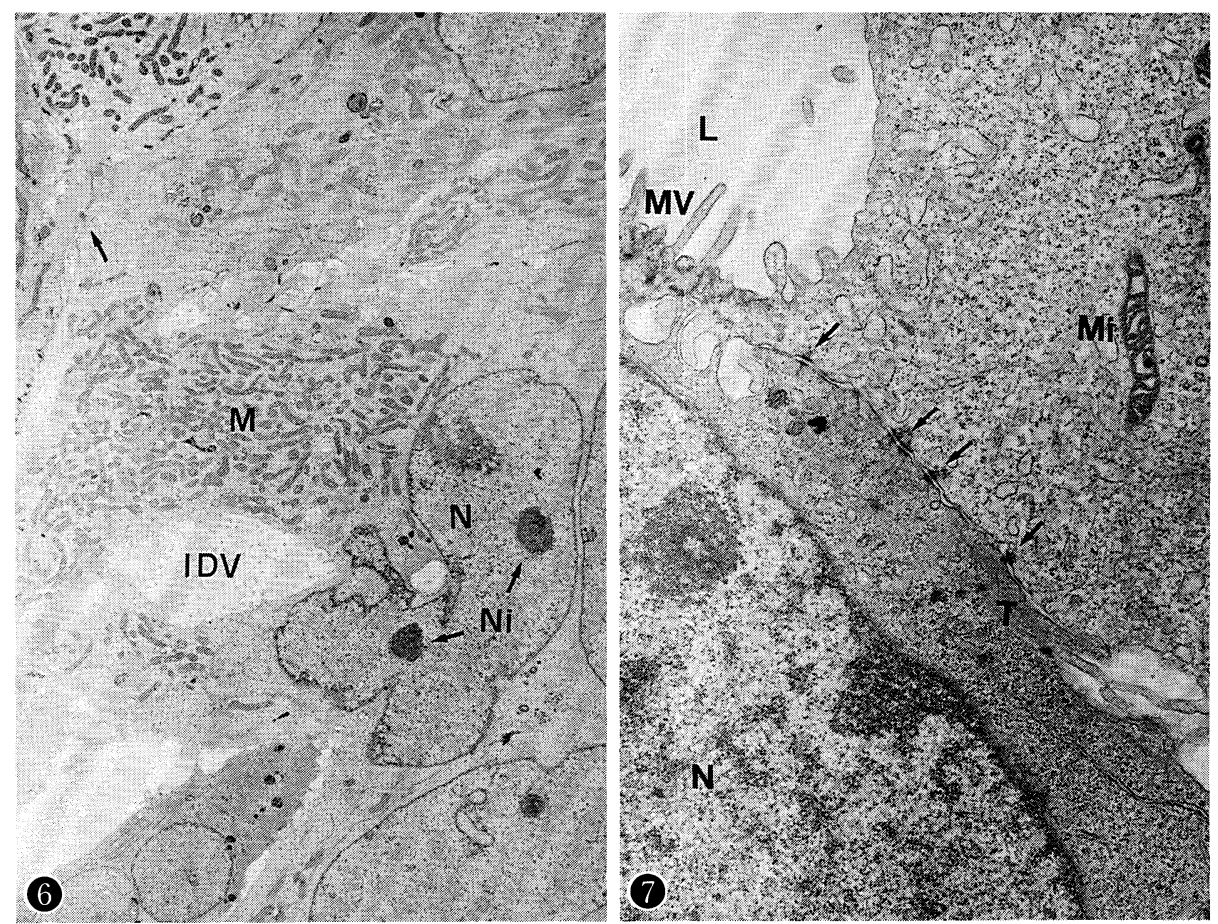

Fig. 6. Ultrastructural morphology of HMA-1 cell showing intracytoplasmic duct-like vacuole (IDV) and desmosome (arrow). $\times 8,100$. M, mitochondria; N, nucleus; $\mathrm{Ni}$, nucleoli.

Fig. 7. Electron micrograph of HMA-1 cell showing desmosomes (arrows), tonofibrils $(\mathrm{T})$, microvilli (MV) $\times 5,600$. L, duct-like lumen; Mi, mitochondria ; N, nucleus.

HMA-1 was also found to have intracytoplasmic duct-like vacuoles, microvilli, desmosomes and tonofibrils (Fig. 7), which are the ultrastructural characteristics of breast carcinoma described by Buehring and Hackett (1974).

\section{Chromosome analysis}

Chromosome irregularity including structural aberrations and abnormal chromosome number was observed in HMA-1 cells. In earlier passages, chromosome abnormalities were often observed: the choromosome number in passage 9 ranged from 40 to 88 . Eighty-two percent of HMA-1 cells had a chromosome number of $2 \mathrm{n}$ and $14 \%$ had that of $4 \mathrm{n}$. In passage 73 , however, the chromosome number was approximately 42 with hypodiploid type. Fig. 8 shows karyotype of a typical HMA-1 cell with a G-banding pattern at the 73rd passage. As shown in Fig. 9, the cell contained 42 chromosomes including 4 abnormal marker chromosomes (Nelson-Rees et al. 1974). The four marker chromosomes could also be found in a cell with 41 chromosomes. Marker chromosome of HeLa S3 cell was 


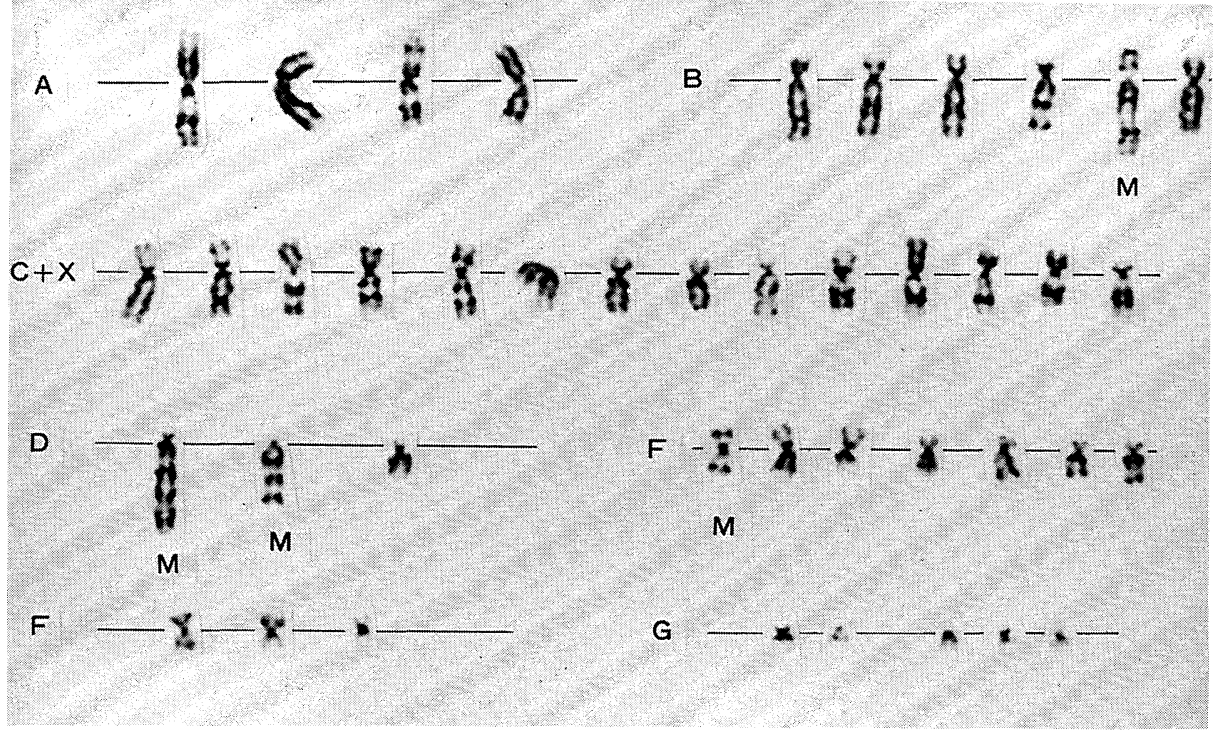

Fig. 8. Karyotype of HMA-1 cell with a G-banding pattern at the 73rd passage. The cell contained 42 chromosomes including 4 abnormal marker chromosomes (M).

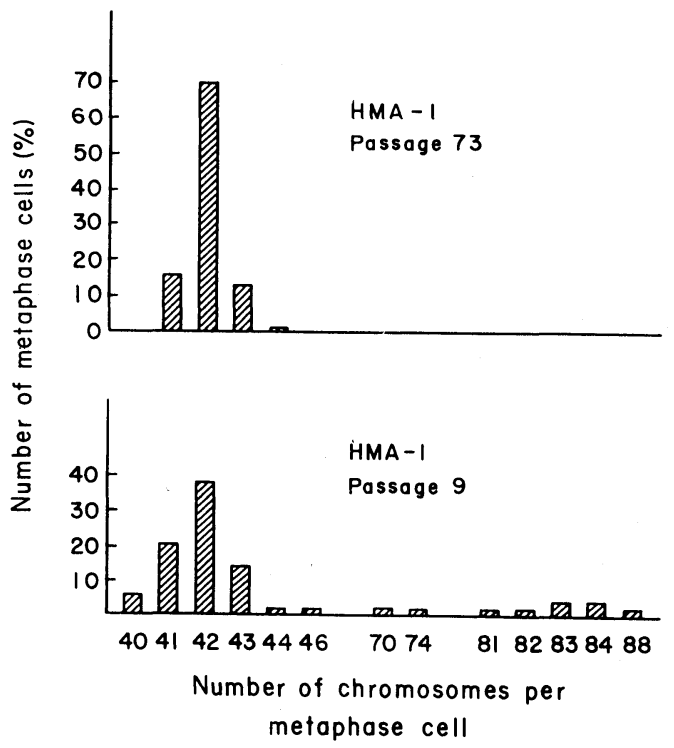

Fig. 9. Chromosome distributions of HMA-1 cell line. Metaphase chromosomes in 100 cells at 9 th and $73 \mathrm{rd}$ passages were counted as described under 'Materials and Methods'. 
not obserbed in the present study.

Isozyme analysis

HMA-1 cell showed the same isozyme pattern as HeLa S3 cell in assays using LDH and NP (Fig. 10), suggesting that origin of HMA-1 cell could be human. Furthermore, isozyme analysis of HMA-1 using G6PD revealed that the cell could

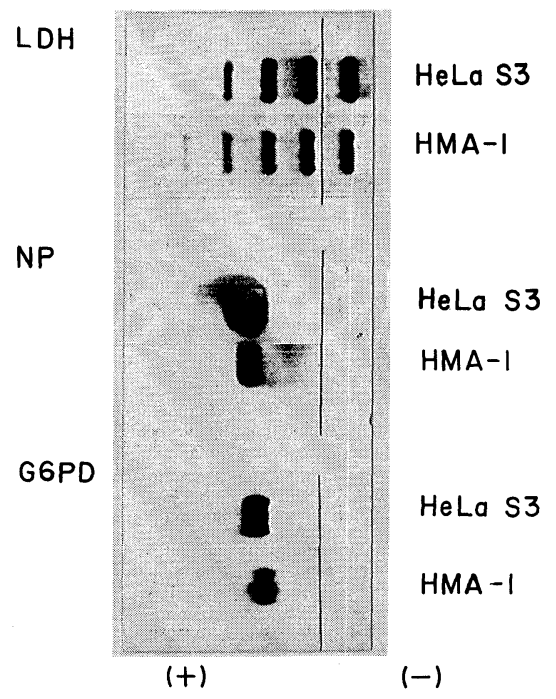

Fig. 10. Isozyme patterens of Hela S3 and HMA-1 cells using LDH, NP and G6PD.

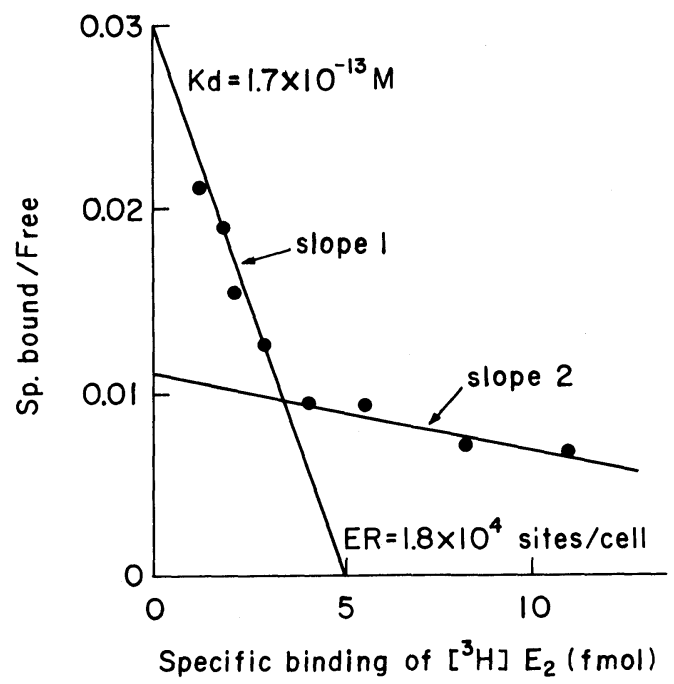

Fig. 11. A typical scatchard plot of $\left[{ }^{3} \mathrm{H}\right] \mathrm{E}_{2}$ binding to HMA-1 cells. 
TABLE 1. Quantitative evaluation of estrogen receptor (ER) in HMA-1 and MCF-7 cell lines defined by whole cell binding assay

\begin{tabular}{ccr}
\hline Cell lines & ER $\left(\times 10^{4}\right.$ sites $/$ cell $)$ & $\mathrm{Kd}(\mathrm{fM})$ \\
\hline HMA-1 & $1.45 \pm 0.35$ & $144 \pm 30$ \\
MCF-7 & $2.40 \pm 0.90$ & $61 \pm 38$ \\
\hline
\end{tabular}
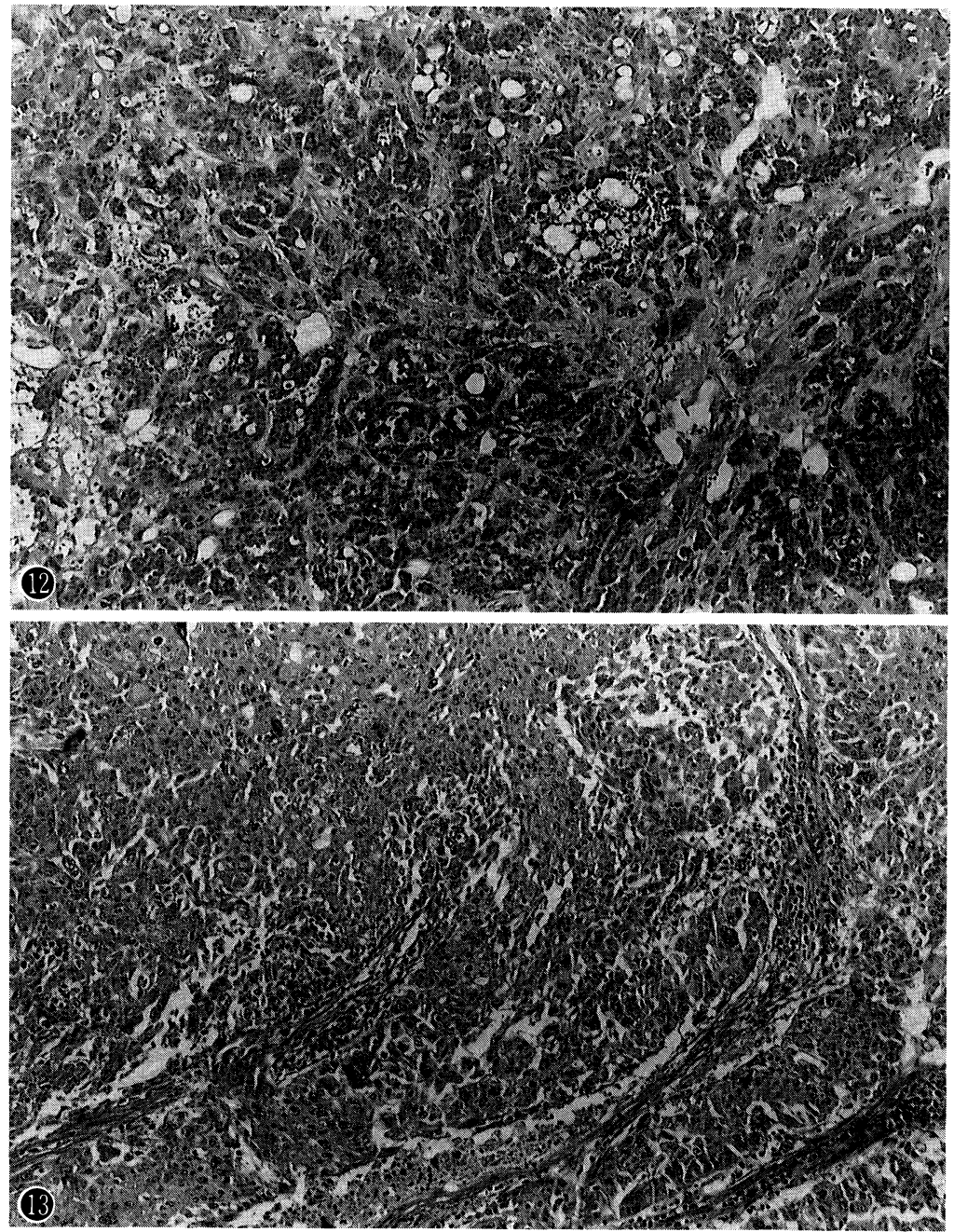

Fig. 12. Histopathology of the tumor implanted in a BALB/c nude mouse, showing well-differentiated adenocarcinoma. $\times 100$.

Fig. 13. Histopathology of primary breast tumor specimen obtained from the patient. The morphology resembles that of implanted tumor (Fig. 12). $\times 100$. 


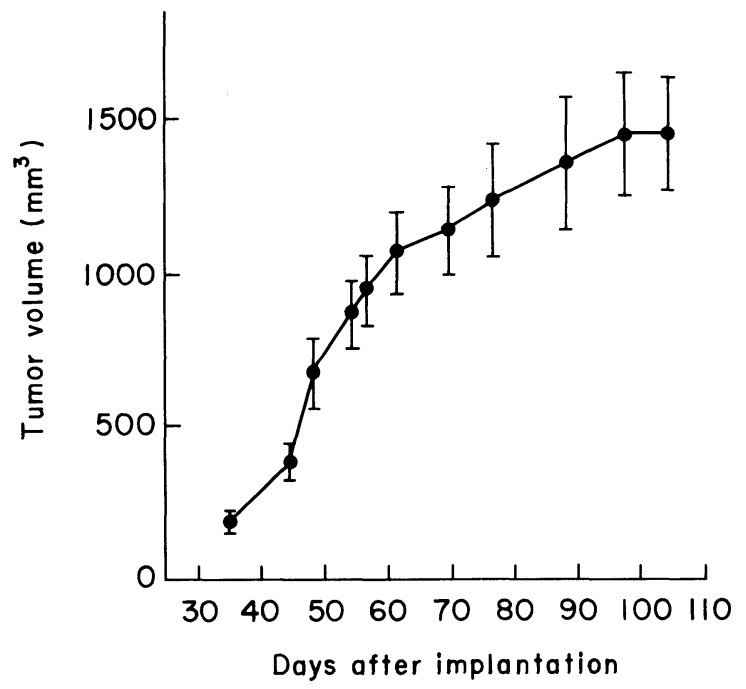

Fig. 14. Growth curve of HMA-1 tumors implanted in BALB/c nude mice.

be type B, Japanese, and excluded the possibility of contamination of HeLa S3 cell with type A (Nordquist et al. 1975: Engel and Young 1978).

\section{Estrogen receptor}

MCF-7 cells were used as a positive control in estrogen receptor (ER) analysis and the amount of ER was compared to that of HMA-1 cells. Fig. 11 shows Scatchard plot of $\left[{ }^{3} \mathrm{H}\right] \mathrm{E}_{2}$ binding to HMA-1 cells in whole-cell binding assay. Both high affinity sites (slope 1) and low affinity sites (Slope 2) were observed in the assay. Quantitative value (mean \pm s.D.) of ER in HMA-1 cells was $1.45 \pm$ $0.35 \times 10^{4}$ sites $/$ cell $(\mathrm{Kd}=144 \pm 30 \mathrm{fM})$, and that of MCF- 7 cells was $2.40 \pm 0.90 \times$ $10^{4}$ sites $/$ cell $(\mathrm{Kd}=61 \pm 38 \mathrm{fM})$, indicating that HMA-1 cell line contained estrogen receptor (Table 1$)$.

\section{Tumorigenicity in vivo}

HMA-1 cells were able to cause tumors in 4 week-old BALB $/ \mathrm{c} / \mathrm{nu} / \mathrm{nu}$ mice. After the cells of $1 \times 10^{8}$ were introduced subcutaneously into these mice, tumors of $9-12 \mathrm{~mm}$ in diameter appeared within 8 weeks. The histopathological examination demonstrated that the tumor was well-differentiated papillary carcinoma (Fig. 12) resembling the histology of primary breast tumor of the patient (Fig. 13). Size of the tumors was measured as Meterials and Methods, and Fig. 14 shows growth curve of HMA-1 tumors implanted in nude mice. The doubling time of tumor was calculated to be 10 days from the growth curve. 


\section{Discussion}

Cells from mammary carcinomas have been one of the most difficult human tumor-derived cells to cultivate and have grown poorly as xenografts in the nude mice. Successful long-term growth of tumor cells from primary breast tumor explants has been rare and the majority of breast cancer-derived cell lines have been of metastatic origin (Engel and Young 1978). One of the possible explanations for the difficulty is that the cell growth of breast carcinoma may depend on effects of hormones and growth factors (Aakvaag et al. 1990). In achieving continuous cultures of breast tumor cell lines many technical difficulties have been reported (Whitecarver 1974; Cailleau 1975). With the use of advanced technology including a new culture medium several investigators have described the isolation and characterization of tumor populations (Band et al. 1989, 1990; Petersen et al. 1990).

As described in this paper, we have established a new human mammary carcinoma cell line, HMA-1, derived from ascitic effusion of a breast cancer patient. The cell line showed a good cell growth ability in monolayer fashion with a doubling time of $46 \mathrm{hr}$. The most probable explanation for our success could be that we collected the breast cancer cells from the ascitic effusion which might contain lively cells, and established the continuous culture when comtaminating fibrobalsts decreased in growth rate. The morphological analysis revealed it to be an epithelial cell line in accordance with the histology of parental tumor. Furthermore, electron microscopic analysis revealed that the HMA-1 cells contain intracytoplasmic duct-like vacuoles, microvilli, desmosomes and tonofibrils, which are characteristic of human breast carcinoma.

We have confirmed that the cells contain estrogen receptor, although the quantitative value of estrogen receptor (binding sites/cell) is relativery low as compared to that of MCF-7 cells. Estradiol stimulated the cell growth, but Tamoxifen, an anti-estrogen agent, induced a dose-dependent decrease in the cell growth rate. This is one of the most striking characteristics of HMA-1, suggesting that the cell line could be utilized in endocrine assays to examine hormonal effects of anti-estrogen agents in clinical trials.

In tumorigenicity assay the HMA-1 cells produced tumors in BALB/c nude mice after subcutaneous heteroinoculation of cells, indicating that the cell line has an ability to be xenografted for in vivo experiments such as targeting immunotherapy model using antibodies recognizing tumor-associated antigens. We are now investigating expressions of breast tumor-associated antigens in the cell line.

In view of the degree of antigenic heterogeneity which has been observed in most human carcinomas, multidisciplinary research using a cocktail of cell lines is essential for the management of breast cancer. More extensive investigations to determine whether the cell line has a property to be applied to the experimental studies will be required. 


\section{References}

1) Aakvaag, A., Utaaker, E., Thorsen, T., Lea, O.A. \& Lahooti, H. (1990) Growth control of human mammary cancer cells (MCF-7 cells) in culture : Effect of estradiol and growth factors in serum-containing medium. Cancer Res., 50, 7806-7810.

2) Band, V., Zajchowski, D., Stenman, G., Morton, C.C., Kulesa, V., Connolly, J. \& Sager, R. (1989) A newly established metastatic breast tumor cell line with integrated amplified copies of erbB-2 and double minute chromosomes. Genes Chromosomes Cancer, 1, 48-58.

3) Band, V., Zajchowski, D., Swisshelm, K., Trask, D., Kulesa, V., Cohen, C., Connolly, J. \& Sager, R. (1990) Tumor progression in four mammary epithelial cell lines derived from the same patient. Cancer Res., 50, 7351-7357.

4) Buehring, G.C. \& Hackett, A.J. (1974) Human breast tumor cell lines: Identity evaluation by ultrastructure. J. Natl. Cancer Inst., 53, 621-629.

5) Butler, W.B., Kelsey, W.H. \& Goran, N. (1981) Effects of serum and insulin on the sensitivity of the human breast cancer cell line MCF-7 to estrogen and antiestrogens. Cancer Res., 41, 82-88.

6) Breast Cancer Task Force Cell Culture Bank, Current Inventory (1977) Rockville, Md., EG \& G/Mason Research Institute.

7) Cailleau, R.M. (1975) Old and new problems in human tumor cell cultivation. In : Human Tumor Cells in Vitro, edited by J. Fogh, Plenum Press, New York, pp. 79-114.

8) Cailleau, R.M., Young, R., Olive, M. \& Reeves, W.J., Jr. (1974) Breast tumor cell lines from pleural effusions. J. Natl. Cancer Inst., 53, 661-674.

9) Cameron, G. \& Chambers, R. (1937) Neoplasm studies III. Organization of cells of human tumors in tissue culture. Am. J. Cancer, 30, 115-129.

10) Chu, M.Y., Hagerty, M.G., Tibberts, L.M., Sato, S., Cummings, F.J., Bogaars, H.A., Leduc, E.H. \& Calabresi, P. (1985) Differential characteristics of two newly established human breast carcinoma cells lines. Cancer Res., 45, 1357-1366.

11) Engel, L.W. \& Young, N.A. (1978) Human breast carcinoma cells in continuous culture: A review. Cancer Res., 38, 4327-4339.

12) Engel, L.W., Young, N.A., Tralka, T.S., Lippman, M.A., O’Brien, S.J. \& Joyce, M.J. (1978) Establishment and characterization of three new countinuous cell lines derived from human breast carcinomas. Cancer Res., 38, 3352-3364.

13) Gottardis, M.M., Wagner, R.J., Borden, E.C. \& Jordan, V.G. (1989) Differential ability of antiestrogens to stimulate breast cancer cells (MCF-7) growth in vivo and in vitro. Cancer Res., 49, 4765-4769.

14) Lasfargues, E.Y. \& Ozzello, L. (1958) Cultivation of human breast carcinomas. $J$. Natl. Cancer Inst., 21, 1131-1147.

15) Nelson-Rees, W.A., Flandermeyer, R.R. \& Hawthorne, P.K. (1974) Banded marker chromosomes as indicators of interspecies cellular contamination. Science, 184, 10931096.

16) Nordquist, R.E., Ishmael, D.R., Lovig, C.A., Hyder, D.M. \& Hoge, A.F. (1975) The tissue culture and morphology of human breast tumor cell line BOT-2. Cancer Res., 35, 3100-3105.

17) Osborne, C.K., Hobbs, K. \& Clark, G.M. (1985) Effects of estrogens and antiestrogens on the growth of human breast cancer cells in athymic nude mice. Cancer Res., 45, 584-590.

18) Petersen, O.W., van Deurs, B., Nielsen, K.V., Madsen, M.W., Laursen, I., Balslev, I. \& Briand, P. (1990) Differential tumorigenicity of two autologous human breast carcinoma cell lines, HMT-3909S1 and HMT-3909S8, established in serum-free medium. Cancer Res., 50, 1257-1270.

19) Smith, H.S., Wolman, S.R. \& Hackett, A.J. (1984) The biology of breast cancer at 
the celular level. Biochem. Biophys. Acta, 738, 103-123.

20) Sommers, C.L., Papageorge, A., Wilding, G. \& Gelman, E.P. (1990) Growth properties and tumorigenesis of MCF-7 cells transfected with isogenic mutants of ras ${ }^{\mathrm{H}}$. Cancer Res., 50, 67-71.

21) Soule, H.D., Vazquez, J., Long, A., Albert, S. \& Brenan, M. (1973) A human cell line from a pleural effusion derived from a breast carcinoma. J. Natl. Cancer Inst., 51, 1409-1413.

22) Sutherland, R.L., Green, M.D., Hall, R.R., Reddel, R.R. \& Taylor, I.W. (1983) Tamoxifen induces the accumulation of MCF-7 human mammary carcinoma cells in $\mathrm{G}_{0} / \mathrm{G}_{1}$ phase of the cell. Eur. J. Cancer Clin. Oncol., 19, 615-621.

23) Trempe, G. \& Fogh, J. (1973) Variation in characteristics of human tumor cell lines derived from similar tumors. In Vitro, 8, 433-439.

24) Whitecarver, J. (1974) Problems of in vitro culture of human mammary tumor cells. J. Invest. Dermatol., 63, 58-64. 